This item was submitted to Loughborough's Research Repository by the author.

Items in Figshare are protected by copyright, with all rights reserved, unless otherwise indicated.

\title{
Thermo-mechanical characteristics and reliability of die-attach through self- propagating exothermic reaction bonding
}

\author{
PLEASE CITE THE PUBLISHED VERSION
}

https://doi.org/10.1109/TCPMT.2021.3108017

PUBLISHER

IEEE

VERSION

AM (Accepted Manuscript)

\section{PUBLISHER STATEMENT}

Personal use of this material is permitted. Permission from IEEE must be obtained for all other uses, in any current or future media, including reprinting/republishing this material for advertising or promotional purposes, creating new collective works, for resale or redistribution to servers or lists, or reuse of any copyrighted component of this work in other works.

\section{LICENCE}

\section{All Rights Reserved}

\section{REPOSITORY RECORD}

Liang, Shuibao, Yi Zhong, Stuart Robertson, Allan Liu, Zhaoxia Zhou, and Changqing Liu. 2021. "Thermomechanical Characteristics and Reliability of Die-attach Through Self-propagating Exothermic Reaction Bonding". Loughborough University. https://hdl.handle.net/2134/16698022.v1. 


\title{
Thermo-mechanical Characteristics and Reliability of Die-attach through Self-propagating Exothermic Reaction Bonding
}

\author{
Shuibao Liang, Yi Zhong, Stuart Robertson, Allan Liu, Zhaoxia Zhou and Changqing Liu, Senior Member, IEEE
}

\begin{abstract}
Self-propagating exothermic reactions (SPER) provide intense localized heat sufficient for bonding metals or alloys with minimal heat excursion to the components, which shows great potential for the die attach in power electronics packaging. However, the reliability of such formed joints is yet to be fully understood owing to a wide range of defects involved in the instantaneous propagating reaction and heating/cooling. In this work, the finite element analysis is performed to understand the thermal transfer and mechanical responses of materials to the SPER bonding for the die attach of Si device onto direct bonded copper (DBC) substrate with $\mathrm{Sn-3.0Ag-0.5Cu}$ solder. The simulation has been validated using the temperature distribution in SPER bonding, which shows a good agreement with the actual measured results. Moreover, a systematic investigation on the mechanical responses due to thermal mismatch reveals their effects on the thermal stress of interfaces and bonding reliability. ${ }^{1}$
\end{abstract}

Index Terms-thermo-mechanical response, phase-change behaviour, residual stress, void, reliability, numerical simulation.

\section{INTRODUCTION}

Self-propagating exothermic reaction (SPER) of metallic multilayered foils can be used for bonding temperaturesensitive electronics components at low ambient temperatures, thanks to the highly concentrated local heat energy $(\sim 1300 \mathrm{~J} / \mathrm{g})$ and the self-propagating rate $(0.01-30 \mathrm{~m} / \mathrm{s})[1-3]$. The recent study [4] showed the potential of the Ni/Al nanofoil acting as a moving heat source to melt solder and form interconnection at low ambient temperatures, hence the minimal thermal impact on the adjacent components during bonding. For widebandgap (WBG), where die-attach in power devices is anticipated to operate at high power and temperature (likely exceeding $300{ }^{\circ} \mathrm{C}$ ). However, bonding process for die-attach at a low ambient temperature is desirable in order to minimize deterioration of device caused by thermal excursion, thus achieve the enhanced performance and reliability. Wang et al. [5] attempted and successfully attached Si die onto $\mathrm{Cu}$ using the SPER process at $25{ }^{\circ} \mathrm{C}$, where the ambient temperature

This work was supported by two EPSRC research grants (UK): (i) Underpinning Power Electronics 2017 - Heterogeneous Integration (HI) project (Grant No. EP/R004501/1), and (ii) Quasi-ambient bonding to enable cost-effective high temperature $\mathrm{Pb}$-free solder interconnects (QAB) project (Grant No. EP/R032203/1).

S. Liang, Y. Zhong, A. Liu and C. Liu are with the Wolfson School of Mechanical, Electrical and Manufacturing Engineering, Loughborough University, Loughborough LE11 3TU, U.K. (e-mail: c.liu@lboro.ac.uk).

S. Robertson and Z. Zhou are with the Loughborough Materials Characterization Centre, Department of Materials, Loughborough University, Loughborough LE11 3TU, U.K. was significantly lower than the conventional solder reflow temperature $\left(>200^{\circ} \mathrm{C}\right)$.

Many studies $[4,6]$ found the void formation at the bonded interface in the joints formed by SPER of nanofoils, these voids greatly undermine the performance and reliability of the interconnects. Voids could arise from the volume shrinkage due to the phase changes, which is related to the temperature changes of materials. Thus, the thermal transfer behaviour of materials is of vital importance to the optimization of SPER bonding process. Some studies $[7,8]$ simulated the temperature distribution as a result of thermal transfer through different materials during SPER bonding. However, their simulations consider neither the latent heat, nor temperaturedependent natures of the materials. Although there are lots of studies on the formation of voids in the solder joints formed by the conventional reflow process or transient liquid phase bonding process [9], the void formation in SPER bonding is yet to be understood.

Moreover, the difference in coefficients of thermal expansion (CTE) of the materials in SPER bonding induces the thermal stress and stress concentration. The stress concentration can be potentially released as voids and cracks develop at the bonding interfaces. Owing to the extremely narrow melting region and heat-affected zone, it is almost impossible to physically quantify the stress/strain distributions during and after the SPER bonding process, let alone any further understanding of their influence on the reliability of the SPER bonded joints. Therefore, numerical approach through modelling presents a significant advantage in prediction of the stress/strain distribution. Kanetsuki et al. [10] proposed a stress balance model to explain the void and crack generation mechanisms during SPER bonding, but no validation was provided due to the unknown stress distribution. Our recent model [11] has included the thermo-mechanical behavior of the $\mathrm{Sn} / \mathrm{Cu}$ interconnects during SPER bonding, but the fluid flow and viscoplastic behaviour of solder and their effects on the joint reliability were not considered.

In this study, the Si power device attached with Sn-3.0Ag$0.5 \mathrm{Cu}$ (SAC) solder alloy onto direct bonded copper (DBC) substrate by SPER of $\mathrm{Ni} / \mathrm{Al}$ nanofoil, is systematically investigated by considering heat transfer, fluid flow, and temperature-dependent elastic-plastic/plastic deformations of materials in SPER process. While the predicted temperature distribution during SPER bonding is verified by experimental work, we have also examined the mechanical behaviour of the bonded structures induced by thermal mismatch and its influence on the joint reliability. 


\section{MeTHODOLOGY}

The test vehicle of die-attach provided by Dynex Semiconductor Ltd and its configuration are shown in Fig. 1(a), where a Si die is attached to the DBC by SPER bonding with three interlayers (SAC/nanofoil/SAC) of a total thickness of $90 \mu \mathrm{m}$. The $\mathrm{Ni} / \mathrm{Al}$ nanofoil ( $40 \mu \mathrm{m}$ thick) was ignited with an electrical spark, and the SPER bonding was conducted under a pressure of $0.5 \mathrm{MPa}$ applied on the top of stacked structure at the ambient temperature. In the simulation, the thin metallization layers on both Si die and DBC substrate are not included; as such a two-dimensional model for FE analysis is shown in Fig. 1(b). Moreover, a K-type thermocouple was fixed at the $\mathrm{Cu}$ substrate $0.1 \mathrm{~mm}$ away from the solder/DBC interface during SPER bonding and the recorded temperature has been compared with the simulation results. The crosssections of the bonded samples were prepared, and subsequently examined under a JEOL 7100F field emission gun scanning electron microscope (FEGSEM) to observe the microstructure and interfacial morphologies.

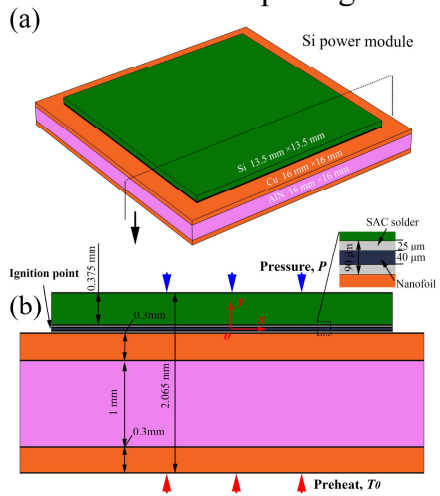

Fig. 1 Schematic diagram of a Si power module (a) and two-dimensional geometric model (b) used in numerical simulation.

\section{A. Heat Transfer and Fluid Flow}

Once initiated, SPER of the Ni/Al nanofoil releases massive local heat, the temperature $T$ in the interconnect obeys:

$$
\rho C_{p}\left(\frac{\partial T}{\partial t}+\boldsymbol{u} \cdot \nabla T\right)+\nabla \cdot(-k \nabla T)=q,
$$

where $C_{p}, \rho$ and $k$ are respectively the specific heat capacity, density and thermal conductivity; the last term is the volumetric heat source. The ambient temperature is set to $T_{e n v}$ $=25^{\circ} \mathrm{C}$ and the thermal boundary $q_{0}=h \cdot\left(T_{e n v}-T\right)$ is applied to the surfaces around the bonded structure, where $h$ is the convective heat transfer coefficient. The value of $h$ for the bottom surface of DBC is set to be $600 \mathrm{~W} /\left(\mathrm{m}^{2} \cdot \mathrm{K}\right), h=100$ $\mathrm{W} /\left(\mathrm{m}^{2} \cdot \mathrm{K}\right)$ for the top surface of Si die, and $h=25 \mathrm{~W} /\left(\mathrm{m}^{2} \cdot \mathrm{K}\right)$ for the rest surrounding boundaries, where the surface temperature and emissivity are assigned to be $25^{\circ} \mathrm{C}$ and 0.5 .

The heat released from SPER of nanofoil layer is regarded as a moving heat source and it is expressed as:

$$
q_{1}(x, t)=Q_{s} \cdot \operatorname{rect}\left(d_{n}-v t\right),
$$

where the heat released rate $Q_{s}=4.54 \times 10^{14} \mathrm{~W} / \mathrm{m}^{3}$ [12], $d_{\mathrm{n}}=x+0.5 l_{\mathrm{f}}$ and $l_{\mathrm{f}}$ is the length of the nanofoil, the propagating velocity $v$ of the reaction is set as $v=5.03 \mathrm{~m} / \mathrm{s}$, which is obtained from the estimation of the experimental results. The rectangular function term is defined as:

$$
\operatorname{rect}\left(d_{n}-v t\right)= \begin{cases}0 & \left|d_{n}-v t\right|>l_{r} / 2 \\ 1 & \left|d_{n}-v t\right| \leq l_{r} / 2\end{cases}
$$

where the reaction zone length $l_{r}=100 \mu \mathrm{m}$.

During the SPER of $\mathrm{Ni} / \mathrm{Al}$ nanofoil, the nanofoil can convert into $\mathrm{Ni}-\mathrm{Al}$ metallics [8]. A variable $p$ is used to present the state of the nanofoil, and $p$ is determined by:

$$
p=\left\{\begin{array}{cc}
1 & d_{n}<v t-l_{r} / 2 \\
\left(1+\sin \left[\left(v t-d_{n}\right) / l_{r}\right]\right) / 2 & \text { else } \\
0 & d_{n}>v t+l_{r} / 2
\end{array} .\right.
$$

Then, the material properties of the nanofoil can be obtained by $M_{f}=p M_{r f}+(1-p) M_{u f}$, where $M_{\mathrm{rf}}$ and $M_{\mathrm{uf}}$ are the properties of reacted and unreacted nanofoils, respectively.

In addition, the effect of phase change of SAC solder, i.e., melting and solidification, on thermal transfer can be described by the apparent heat capacity method. The heat capacity of the solder is written as:

$$
C_{p s}=C_{p, s} \cdot(1-\beta)+C_{p, l} \cdot \beta+L_{s \rightarrow l} \cdot d \beta / d T,
$$

where $C_{p, s}$ and $C_{p, l}$ are respectively the capacities of the solid solder and liquid solder, $\beta$ is the percent volume occupied by liquid phase, the latent heat $L_{s \rightarrow l}=61.03 \mathrm{KJ} / \mathrm{Kg}[13]$.

The flow velocity $(\boldsymbol{u})$ of the SAC solder during the SPER bonding is governed by the Navier-Stokes equation:

$$
\frac{\partial \boldsymbol{u}}{\partial t}+(\boldsymbol{u} \cdot \nabla) \boldsymbol{u}=-\frac{\nabla P}{\rho}+\frac{\mu}{\rho} \nabla^{2} \boldsymbol{u}+\rho \boldsymbol{g}\left[1-\alpha\left(T-T_{0}\right)\right]+\boldsymbol{F}_{s}
$$

where $P, \mu, \alpha$ and $g$ is the fluid pressure, melt viscosity, thermal expansivity and gravity acceleration, respectively. The last term $\boldsymbol{F}_{\mathrm{s}}$ in Eq. (6) is used to damp the acceleration resulting from the momentum equation and thereby imitates solid behaviour [14], and it can be written as $\boldsymbol{F}_{s}=(1-\beta)^{2} n \boldsymbol{u} /\left(\beta^{3}+m\right)$, where $m=10^{5}$ and $n=0.001$.

\section{B. Thermal Stress and J-integral}

Assuming zero displacement along $y$ direction of the bottom surface of DBC and the left end of bottom surface is fixed, the CTE mismatch induced thermal stress $\sigma_{i j}$ is governed by:

$$
\frac{\partial \boldsymbol{\sigma}_{i j}}{\partial \boldsymbol{x}_{i}}=0
$$


The plastic deformation of $\mathrm{Cu}$ is described by an isotropic hardening model $d \sigma / d \varepsilon=E_{t}$, where $E_{t}$ is the tangent modulus. The mechanical behaviour of the $\mathrm{Ni} / \mathrm{Al}$ nanofoil is described by the perfectly plastic model, while the mechanical behaviour of SAC solder can be defined by the Anand model, and the parameters are listed in Table I [15]. The relief of stress and strain due to the melting of solder, $\mathrm{Al}$ and $\mathrm{NiAl}$ in nanofoil [8] should also be considered, thus an activation factor $\left(\sim 10^{-5}\right)$ is introduced to scale the strain tensor sufficiently at melting region, in order to simulate their mechanical responses.

$$
\text { TABLE I }
$$

PARAMETERS OF THE ANAND MODEL FOR SOLDER

\begin{tabular}{cccc}
\hline \hline Properties & Symbol & Unit & Value \\
\hline Deformation resistance sensitivity & $\eta$ & - & 0.07 \\
Activation energy & $Q / R$ & $\mathrm{~K}$ & 9400 \\
Stress sensitivity & $m_{0}$ & - & 0.303 \\
Stress multiplier & $\xi$ & - & 1.5 \\
Pre-exponential factor & $A$ & $1 / \mathrm{s}$ & $4.1 \times 10^{6}$ \\
Deformation resistance saturation & $s_{0}$ & $\mathrm{MPa}$ & 12.41 \\
coefficient & $s$ & $\mathrm{MPa}$ & 13.79 \\
Deformation resistance initial value & $a$ & - & 1.3 \\
Hardening sensitivity & $h_{0}$ & $\mathrm{MPa}$ & 1378.95 \\
Hardening coefficient & \multicolumn{2}{c}{}
\end{tabular}

To evaluate the probability of crack propagation near the interfaces, a path independent line integral (i.e., $J$-integral) along a counterclockwise contour $(\Gamma)$ surrounding a crack tip is calculated. The $J$-integral is defined as [16]:

$$
J=\int_{\Gamma}\left(W n_{x}-T_{\sigma i} \frac{\partial u_{d i}}{\partial x}\right) d s,
$$

$W$ is the strain energy density, and $\boldsymbol{T}_{\sigma}$ is the traction vector.

\section{Material properties}

Material properties are temperature-dependent during SPER bonding in the simulation. At the solid-liquid interface, the properties of SAC solder are the linear combination of the properties at its solid or liquid states. The properties of the other materials are provided in Table II [17-21]. The dynamic viscosity of the liquid SAC solder is given by $\mu=\mu_{0} \exp \left(E_{\mu} / R T\right)$, and $\mu_{0}=4.58 \times 10^{-4} \mathrm{~Pa} \cdot \mathrm{s}, E_{\mu}=6.89 \times 10^{3} \mathrm{~J} / \mathrm{mol}[22]$.

TABLE II

\begin{tabular}{|c|c|c|c|c|c|c|c|}
\hline Properties & Density $\left(\mathrm{Kg} \mathrm{m}^{-3}\right)$ & $\begin{array}{l}\text { Thermal conductivity } \\
\left(\mathrm{W} \mathrm{m}^{-1} \mathrm{~K}^{-1}\right)\end{array}$ & $\begin{array}{l}\text { Specific heat } \\
\left(\mathrm{J} \mathrm{Kg}^{-1} \mathrm{~K}^{-1}\right)\end{array}$ & CTE $\left(\mathrm{ppm} \mathrm{K}^{-1}\right)$ & $\begin{array}{c}\text { Young's } \\
\text { modulus (GPa) }\end{array}$ & $\begin{array}{l}\text { Poisson's } \\
\text { ratio }\end{array}$ & Yield strength (MPa) \\
\hline $\mathrm{Cu}$ & $9062.2-0.39 T$ & $420-0.068 T$ & $342.764+0.13 T$ & $\begin{array}{c}11.05+2.7 \times 10^{-8} T- \\
3.16 \times 10^{-11} T^{2} \\
\end{array}$ & 140.8-0.047T & 0.33 & $222.4-0.35(T-273)$ \\
\hline AlN & 3260 & $319^{\mathrm{a}}$ & $\begin{array}{l}1118.4+8.17 \times 10^{-} \\
{ }^{2} T-3.65 \times 10^{7} T^{2}\end{array}$ & $2.8^{\mathrm{a}}$ & $\begin{array}{c}310.2-0.0247 T \mathrm{e}^{-} \\
533 / \mathrm{T}\end{array}$ & 0.23 & - \\
\hline Nanofoil & 5500 & 152 & 830 & 16.9 & $\begin{array}{c}91.867-0.048(T- \\
273) \\
\end{array}$ & 0.31 & $151.09-0.07(T-273)$ \\
\hline $\begin{array}{l}\text { Reacted } \\
\text { nanofoil }\end{array}$ & 5900 & 60 & 640 & 13.2 & $\begin{array}{c}193-0.04(T- \\
273)\end{array}$ & 0.31 & $543.16-0.126(T-273)$ \\
\hline Solder (S) & $\begin{array}{c}7202.783+2.72 T \\
-0.013 T^{2} \\
\end{array}$ & $58^{\mathrm{a}}$ & $229^{\mathrm{a}}$ & $21.7^{\mathrm{a}}$ & - & - & - \\
\hline Solder (L) & $7452.9-0.662 T$ & $24^{\mathrm{b}}$ & $249^{\mathrm{b}}$ & $29.98+2.01 \times 10^{-3} \mathrm{~T}$ & - & - & - \\
\hline $\mathrm{Si}$ & 2330 & 148 & 712 & 2.6 & 130 & 0.278 & - \\
\hline
\end{tabular}

MATERIALS' PROPERTIES

${ }^{\text {a }}$ These values corresponding to the properties at the room temperature, temperature-dependent properties are assigned in the simulation.

${ }^{b}$ These values corresponding to the properties at the melting point, temperature-dependent properties are assigned in the simulation.

\section{RESULTS AND DISCUSSION}

\section{A. Temperature and Fluid Flow Velocity Distribution}

When the nanofoil's combustion is ignited with an electrical spark, intense heat is released from the propagating SPER and spontaneously transfers to the adjacent layers, resulting in the temperature increases. As shown in Fig. 2, only the temperature distribution near the front of the self-propagating reaction is exhibited due to the large aspect ratio of the considered interconnect structure (see Fig. 1). While the SPER proceeds, the highest temperature at the nanofoil can reach $1303{ }^{\circ} \mathrm{C}$ and $1307{ }^{\circ} \mathrm{C}$ at $t=0.2$ and $t=0.4 \mathrm{~ms}$, respectively. The green isotherm lines in Fig. 2 represent the contour of melting temperature of SAC alloy $\left(\mathrm{T}_{\mathrm{m}} \sim 217^{\circ} \mathrm{C}\right)$ in the adjacent of the nanofoil, marking the phase changes as the SPER propagates.

Note that the temperature in the solder's region is an important factor in determining its wetting behaviour and chemical reaction with the substrate, the temperature profiles along the line $X=-6.7 \times 10^{-3} \mathrm{~m}$ at different times during SPER bonding are shown in Fig. 3. At $t=0.005 \mathrm{~ms}$, the SAC solder remains in its solid state as the temperature is lower than its melting point. At $t=0.025 \mathrm{~ms}$, the solder begins to melt and is likely to react with DBC substrate. At $t=0.125 \mathrm{~ms}$, the SAC melting region expands due to further temperature increase. From $t=0.225 \mathrm{~ms}$ to $t=0.25 \mathrm{~ms}$, while the SAC solder in contact with the Si die still maintains molten state, the SAC solder in contact with the DBC may start to solidify as it has cooled to melting point or below. The time for SAC solder to solidify mainly depends on the thermal diffusivity of the adjacent materials. The higher thermal diffusivity of $\mathrm{Cu}$ $\left(\sim 1.11 \times 10^{-4} \mathrm{~m}^{2} / \mathrm{s}\right)$ in comparison with $\mathrm{Si}\left(\sim 8.8 \times 10^{-5} \mathrm{~m}^{2} / \mathrm{s}\right)$ can accelerate the heat dissipation from the molten solder, resulting in a sooner solidification of the SAC solder near the DBC substrate.

To verify the simulation results of temperature distribution, the experiment with the same $\mathrm{Si}$ power module structure is also carried out to monitor the temperature at $\mathrm{Cu}$ substrate 
near the $\mathrm{DBC} /$ solder interface, and the temperature change during the SPER bonding can be seen in Fig. 4. By comparing the simulation results with the experimental data, the simulation results are in an excellent agreement with the experimental results.

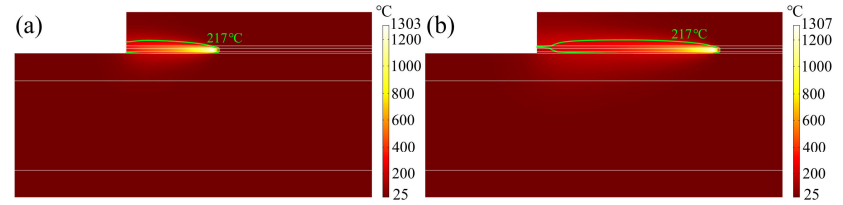

Fig. 2 Temperature distribution in the power module during the SPER bonding at times: (a) $t=0.2 \mathrm{~ms}$; (b) $t=0.4 \mathrm{~ms}$ (the green isotherm lines corresponding to the melting point of the SAC solder).

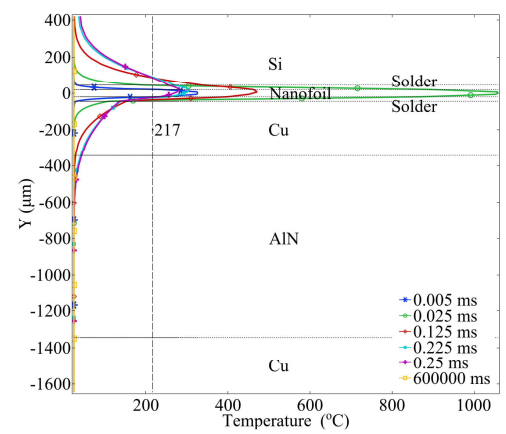

Fig. 3 Temperature distribution along the line $X=-6.7 \times 10^{-3} \mathrm{~m}$ during

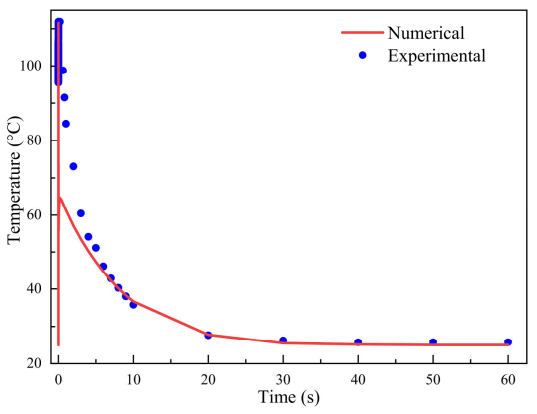

Fig. 4 Comparison of experimentally measured and numerically computed temperature at the $\mathrm{Cu}$ substrate $0.1 \mathrm{~mm}$ from the solder/DBC interface during SPER bonding.

Except for the temperature, the flow velocity of the molten solder can be critical to the melting of solder. The maximum velocity $\sim 1.6 \mu \mathrm{m} / \mathrm{s}$ is likely to occur along the interfaces, particularly when reaching the stage of solidifying between the nanofoil and DBC substrate as seen at the bottom-left corners in Fig. 5 (a) and (b). It is also found that the velocities of the molten solder at the reaction fronts and the solidification boundaries are generally higher than other regions. However, the velocities are relatively small in magnitude and the Rayleigh number is below the critical value, as such they are unlikely to have any apparent effect on heat convection in the soldering process. It is worth of noticing that the velocities at the DBC/SAC interface are greater than that at the $\mathrm{Si} / \mathrm{SAC}$ interface, which is likely attributed to the higher degree of thermal excursion at the $\mathrm{DBC} / \mathrm{SAC}$ interface as indicated in Fig. 2(a).

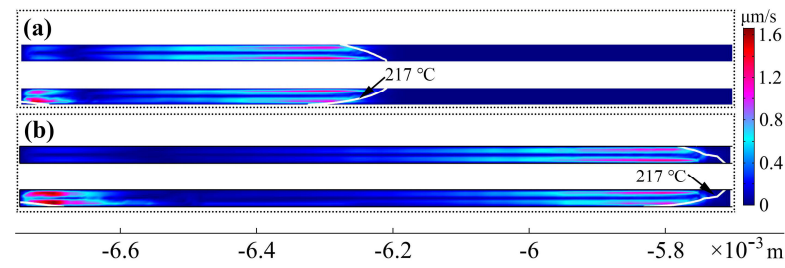

Fig. 5 Magnitudes of flow velocity in the SAC solder during the SPER bonding at times: (a) $t=0.1 \mathrm{~ms}$; (b) $t=0.2 \mathrm{~ms}$.

\section{B. Mechanical Behaviour due to the CTE mismatch}

The mechanical response of materials to the thermal strain causes the increase of thermal stress in the power module during the SPER bonding process. As can be seen in Fig. 6, more heat accumulates in the $\mathrm{Si}$ power device, and the evolution of stress highly depends on the temperature distribution. The stress near the reaction front is relatively high because of the greater CTE mismatch induced strain due to the high temperature gradient, and the maximum von Mises stress can reach $510 \mathrm{MPa}$. As time proceeds from 0.2 to 0.4 ms (Fig. 6a \& b), the maximum von Mises stresses in the solder region close to the $\mathrm{Si} / \mathrm{SAC}$ interface reduced from 325.12 to $10.736 \mathrm{MPa}$, as compared to the values near the SAC/DBC interface from 371.14 to $215.64 \mathrm{MPa}$, respectively. The results also showed the mean values of von Mises stresses in the solder near the $\mathrm{Si} / \mathrm{SAC}$ interface decresed from 3.12 to $0.18 \mathrm{MPa}$, whilst the mean values of von Mises stresses near the SAC/DBC interface increased from 20.48 and $34.568 \mathrm{MPa}$. The decrease in maxium stress of the solder is caused by the melting of the SAC solder, which leads to the stress relief in the regions. The greater stress in the solder close to the SAC/DBC interface implies the greater tendency of the mechanical failure to occur at the SAC/DBC interface.
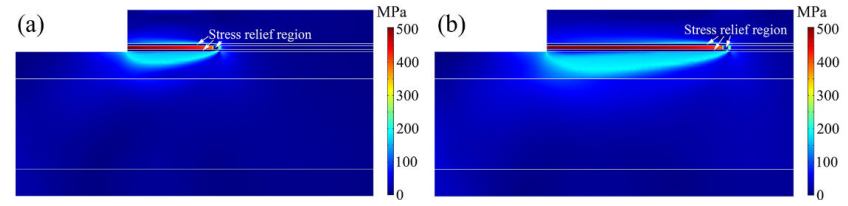

Fig. 6 Von Mises stress in the power module during the SPER bonding at times: (a) $t=0.2 \mathrm{~ms}$; (b) $t=0.4 \mathrm{~ms}$.

The Von Mises stress along the line $X=-6.7 \times 10^{-3} \mathrm{~m}$ during SPER bonding is presented in Fig. 7. It is found that the stress concentration at the $\mathrm{Si} / \mathrm{SAC}$ and $\mathrm{SAC} / \mathrm{DBC}$ interface is high. At $t=0.005 \mathrm{~ms}$, the stress in the solder regions is $\sim 90 \mathrm{MPa}$. As time increases to $0.025 \mathrm{~ms}$, the stress rapidly decreases since the molten of solder. From $t=0.125 \mathrm{~ms}$ to $t=0.25 \mathrm{~ms}$, the stress in the solder matrix is almost zero, the interfacial stress near $\mathrm{Si}$ layer decreases, but the interfacial stress near the DBC layer gradually increases. After $6 \times 10^{5} \mathrm{~ms}$, the temperature of the $\mathrm{Si}$ power device cools down to the room temperature, the solidification of the solder results in the increase of the stress, and the inelastic deformation of materials continues to occur with the stress increasing. 


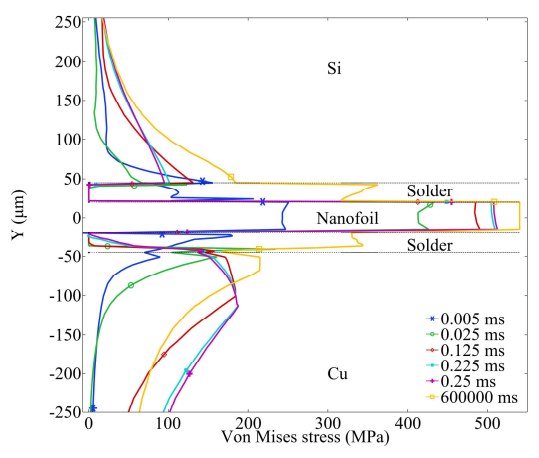

Fig. 7 Von Mises stress along the line $\mathrm{X}=-6.7 \times 10^{-3} \mathrm{~m}$ during bonding.

Fig. 8 presents the Von Mises stress and temperature at Si/SAC, SAC/Nanofoil, Nanofoil/SAC and SAC/DBC interfaces. Except for the SAC/DBC interface, an obvious stress relief phase at the other interfaces is present with a timelength of $0.5 \mathrm{~ms}$ (corresponding to the time-length of the temperature higher than the melting point of the solder in Fig. 8 (b)). This also implies that the stress relief hold time of solder near $\mathrm{DBC}$ is shorter than that near $\mathrm{Si}$. The stress at $\mathrm{SAC} / \mathrm{DBC}$ interface first increases rapidly and then gradually decreases. However, the stress at the other three interfaces increases sharply, but relaxes immediately due to the solder melting, followed by steadily rises due to the cooling with the accompanying solidification of the liquid solder.
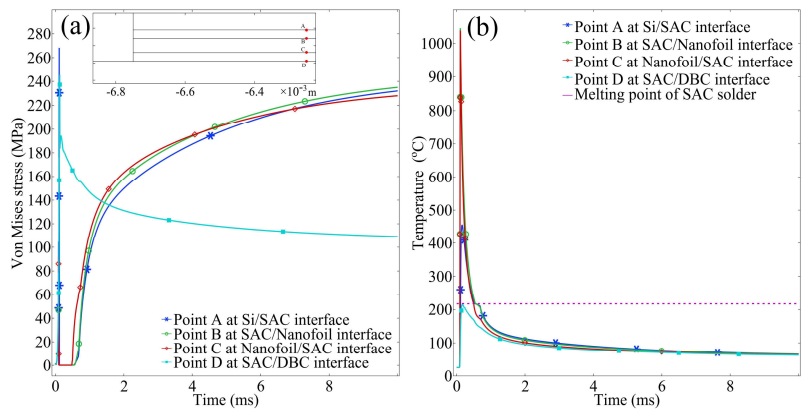

Fig. 8 Von Mises stress (a) and temperature (b) of the points A, B, C and $\mathrm{D}$ respectively at $\mathrm{Si} / \mathrm{SAC}, \mathrm{SAC} /$ Nanofoil, Nanofoil/SAC and SAC/DBC interfaces during SPER bonding.

\section{Residual Stress Analysis}

After the bonding, i.e., the bonded structure cools down to room temperature, the inelastic deformation cannot be recovered, then the residual stress exists in the interconnects. Fig. 9 presents the distribution of the residual stresses along $x$ (longitudinal) and $y$ (through-thickness) directions. It is observed that the maximum longitudinal and throughthickness stresses are both located in the layer of nanofoil as expected. The $x$-component of residual stresses in the $\mathrm{Si}$ and DBC layers are predominantly compressive, evolving into tensile stress in the nanofoil and solder. Interestingly, the longitudinal residual stress is much higher than the throughthickness residual stress in the solder layer (see Fig. 9 (a) and (b)). The estimated average values of the residual von Mises stresses in the solder region near the $\mathrm{Si} / \mathrm{SAC}$ and $\mathrm{SAC} / \mathrm{DBC}$ interface are 331.98 and $331.74 \mathrm{MPa}$ respectively. The maximum residual von Mises stresses in the solder region near the $\mathrm{Si} / \mathrm{SAC}$ interface and $\mathrm{SAC} / \mathrm{DBC}$ interface are 488.14 and 455.97 $\mathrm{MPa}$ respectively. These values are higher than the maximum residual stress ( 245 MPa [23]) in the Sn-based solder interconnects formed by a conventional reflow process due to the higher temperature and constraint deformation in the narrow heat-affected zone of the SPER bonding. The residual stress is higher than the yield strength of the solder alloys ( $30 \mathrm{MPa}[24])$, which can cause plastic deformation of the solder interconnects and promote the crack formation. Therefore, it would be more beneficial if the residual stresses may be minimized to enhance the mechanical integrity of SPER solder bonding structures.
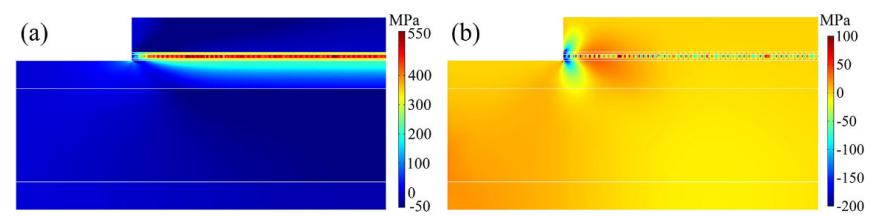

Fig. 9 The distribution of $x$-component (a) and $y$-component (b) of stress in the power module after SPER bonding.

Note that the longitudinal residual stress along interface is important because it is a driving force for crack propagation [25]. Fig. 10(a) shows the high tensile longitudinal stress in the solder regions along the line $X=-6.7 \times 10^{-3} \mathrm{~m}$ after SPER bonding, against the compressive stress in the $\mathrm{Si}$ and DBC layers, which is likely to promote the formation of interfacial voids/cracks. It should be mentioned that susceptibility to void formation depends not only on the magnitude of the residual stresses but also the strength of the bonding interfaces. In the solder region, the residual stress near the $\mathrm{Si} / \mathrm{SAC}$ interface is higher than that near SAC/DBC interface, which can be attributed to the higher Young's modulus of Si compared to $\mathrm{Cu}$ (see Table II). From the through-thickness residual stress distribution shown in Fig. 10(b), it is found that the residual stresses are mostly compressive along the vertical direction, which can reduce the possibility of delamination at the interfaces.

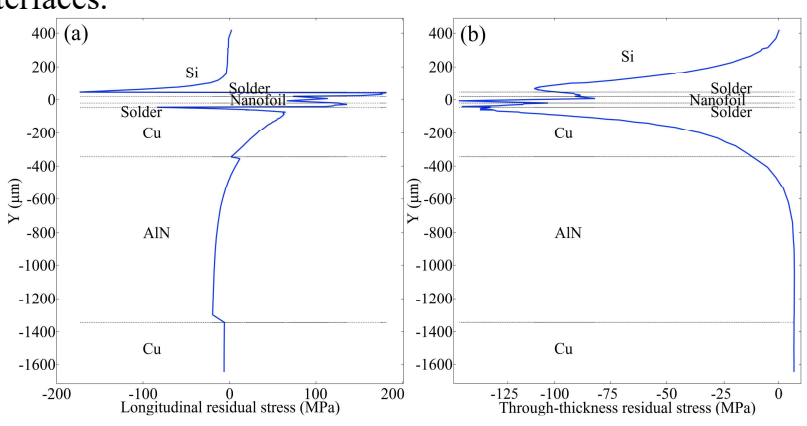

Fig. 10 Longitudinal stress (a) and through-thickness residual stress (b) distributions along the line $\mathrm{X}=-6.7 \times 10^{-3} \mathrm{~m}$ after SPER bonding.

\section{Interfacial Reliability and J-integral}

Note that the non-negligible role of hydrostatic stress and its gradient in driving the vacancies to directionally diffuse 
toward the void [26], and the additional atomic flux due to the stress can be expressed as $J_{s}=-(c D \Omega / K T) \nabla \sigma_{\mathrm{HS}}$, where $c$ is the normalized atomic density, $D$ is the atom diffusivity, $\Omega$ is the atomic volume. Thus, the hydrostatic stress gradient is usually taken as an indicator of void location. The hydrostatic stress and its gradient are defined as [26, 27]:

$$
\begin{gathered}
\sigma_{\mathrm{HS}}=\frac{\sigma_{x}+\sigma_{y}+\sigma_{z}}{3}, \\
\nabla \sigma_{\mathrm{HS}}=\left(\frac{\delta \sigma_{\mathrm{HS}}}{\delta x}, \frac{\delta \sigma_{\mathrm{HS}}}{\delta y}, \frac{\delta \sigma_{\mathrm{HS}}}{\delta z}\right) .
\end{gathered}
$$

Fig. 11 (a) shows the hydrostatic stress distribution along the line $X=-6.7 \times 10^{-3} \mathrm{~m}$ at room temperature after SPER bonding. It can be observed that the hydrostatic stresses in the solder and nanofoil are tensile, and they are compressive in other regions of the bonded structure. This suggests that there exists a sharp gradient of hydrostatic stress along the throughthickness direction of the power module, as can be plotted in Fig. 11(b). There are large hydrostatic stress gradients at the $\mathrm{Si} / \mathrm{SAC}$ and $\mathrm{SAC} / \mathrm{DBC}$ interfaces, and the stress gradient at the DBC/SAC interface is much steeper than that at the $\mathrm{Si} / \mathrm{SAC}$ interface. Since the atomic flux is proportional to the negative of hydrostatic stress [26], high hydrostatic stress gradient at interfaces will drive the directional movement of vacancies, which will accumulate at the interfaces to potentially form the voids. Therefore, the stress gradients at the $\mathrm{Si} / \mathrm{SAC}$ and SAC/DBC interfaces after bonding can become important factors affecting the possibility of void formation.

Although it is found that the formation of voids was mainly attributed to volume shrinkage as well as the trapped air [28]; and the voids were observed at the interface of bonded structures prepared by Ni/Al nanofoil SPER bonding [4], the further details accounting for the void formation still remains unclear. From our experimental results shown in Fig. 12, many voids have been observed, especially near the DBC/SAC interface (Fig. 12(d)). However, the voids near the $\mathrm{Si} / \mathrm{SAC}$ interface are relatively scarce, which is likely attributed to the combination of the prolonged melting, better interfacial wetting due to metalized surface on the die, and the lower hydrostatic stress gradient induced post SPER bonding (Fig. 11). Our simulation and analysis provided the supportive fundamental understanding on the void formation and its effect on the reliability of SPER solder interconnects for die attach, and further clarified the reason of that fracture occurred at the $\mathrm{DBC} / \mathrm{SAC}$ interface which was observed in our experiment.

The high thermal stress has a significant effect on the mechanical reliability of the interconnects, the J-integral can be used to evaluate the probability of crack propagation. In our study, the variations are calculated in J-integral of the crack tips during bonding, at the $\mathrm{Si} / \mathrm{DBC}$ and $\mathrm{SAC} / \mathrm{DBC}$ interfaces. For both cases, the thermo-mechanical behaviour during
SPER bonding is simulated followed by the calculation of Jintegral based on the stress and strain distribution around the crack tips, yielding the J-integral curves shown in Fig. 13. It can be seen that the J-integral of the SAC/DBC interface is greater than that of the $\mathrm{Si} / \mathrm{SAC}$ interface at the early stage of bonding, but J-integral of the SAC/DBC interface evolves with time and become smaller. At the early stage of the bonding, cracks at the SAC/DBC interface are more likely to propagate during the period of solder's melting and solidification, while there is a higher risk of cracking at the $\mathrm{Si} / \mathrm{SAC}$ interface at a later stage given the drastic increase of the J-integral, which would degrade the thermal cycling reliability of the interconnects.
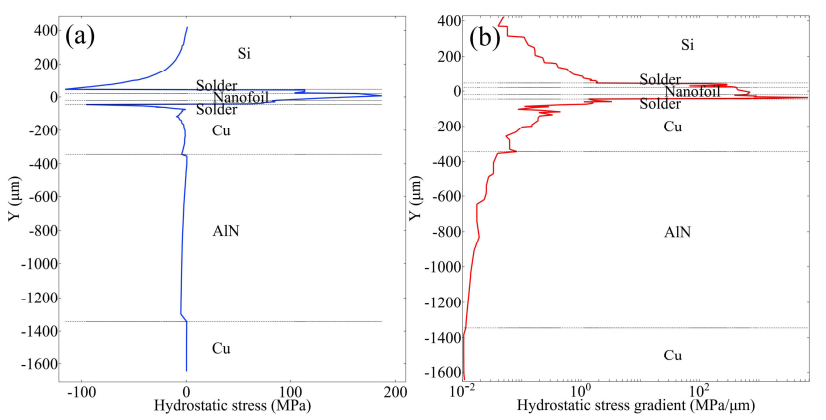

Fig. 11 Hydrostatic stress distribution (a) and hydrostatic stress gradient magnitude (b) along the line $\mathrm{X}=-6.7 \times 10^{-3} \mathrm{~m}$ after SPER bonding.

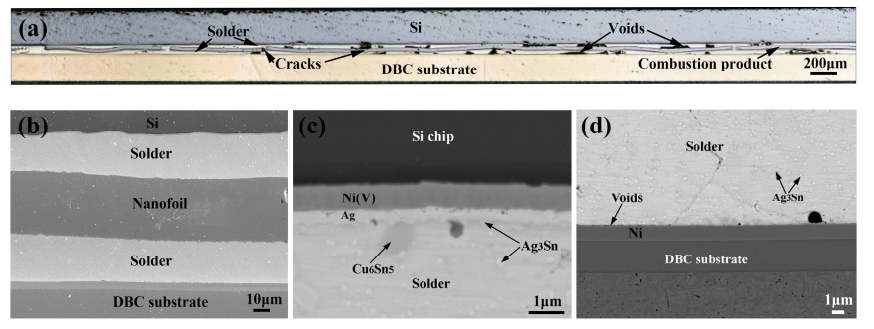

Fig. 12 (a) Optical cross-sectional micrograph of a die-attach bond line; the cross-sectional SEM images of (b) the bonded structure, (c) Si/solder interface and (d) solder/DBC interface.

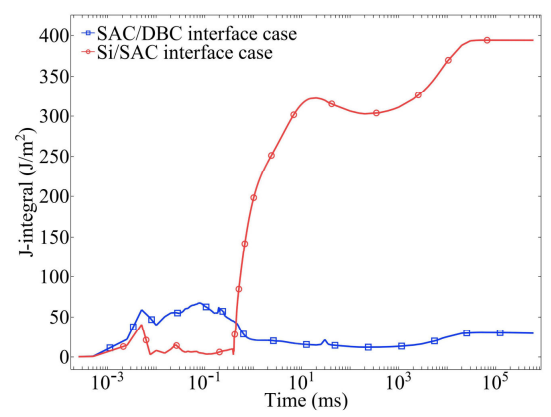

Fig. 13 Time-dependence of J-integrals corresponding to the two cases of a crack respectively at $\mathrm{Si} / \mathrm{SAC}$ and $\mathrm{SAC} / \mathrm{DBC}$ interfaces during bonding.

\section{CONCLUSIONS}

In this study, the Si power device attached with $\mathrm{Sn}-3.0 \mathrm{Ag}-$ $0.5 \mathrm{Cu}$ solder onto DBC substrate by SPER of Ni/Al nanofoil is systematically investigated by numerical simulation. The emphasis is placed on the distribution characteristics of 
temperature, flow velocity and thermal stress. The effects of residual stress and hydrostatic stress on void formation and interfacial reliability are discussed, and the simulated results are verified by experiment. The main conclusions are summarized as follows:

(1) During SPER bonding, the temperature of nanofoil combustion could reach $1307{ }^{\circ} \mathrm{C}$. Results of temperature distribution from the simulation are in an excellent agreement with the experimental results. The intensive localized heat has caused the melting of adjacent SAC solder alloy, and the melting time of the adjacent solder near $\mathrm{Si} / \mathrm{SAC}$ interface is longer than that near SAC/DBC interface due to the less effective heat dissipation through the Si compared to DBC.

(2) As the SPER bonding progresses, more heat accumulates in the nanofoil's region of the power module, and evolution of stress highly depends on the temperature distribution across the entire bonded structure. The melting of the solder causes stress relief, which last shorter time in the solder near SAC/DBC interface than that near $\mathrm{Si} / \mathrm{SAC}$ interface.

(3) After the bonding, higher residual stresses are induced near the $\mathrm{Si} / \mathrm{SAC}$ interface than $\mathrm{SAC} / \mathrm{Cu}$ interface. The residual stresses change from compressive to tensile along the longitudinal $x$-axis at the regions of nanofoil and solder can act as a driving force for crack propagation. The residual stress at $\mathrm{Si} / \mathrm{SAC}$ interface is higher than that at SAC/DBC interface, which can be attributed to the higher Young's modulus of $\mathrm{Si}$ compared to $\mathrm{Cu}$ on DBC.

(4) High hydrostatic stresses along the SAC/DBC and $\mathrm{SAC} / \mathrm{Si}$ interface are inevitable during and after SPER bonding. The hydrostatic stress gradient at SAC/DBC interface is found to be steeper at the early stage of the bonding, implying the likeliness of directional movement of vacancies and accumulation to potentially form the voids, which is confirmed through experimental validation.

(5) The high thermal stress has a significant effect on the mechanical reliability of the interconnects. The J-integral that can be used to evaluate the probability of crack propagation indicates that the J-integral of the SAC/DBC interface is greater than that of the $\mathrm{SAC} / \mathrm{Si}$ interface at the early stage of bonding, but it evolves with time and become smaller. Cracks are more likely to initiate and propagate at the SAC/DBC interface during the initial SPER bonding stage. However, a higher risk of cracking at the $\mathrm{SAC} / \mathrm{Si}$ interface at the later stage.

It is anticipated that the in-depth and comprehensive understanding of the thermo-mechanical behavior of the Si power module with SAC interconnects formed by SPER bonding in this study enables a step forward for the tangible application of SPER bonding in power electronics industry, and the results will assist the process optimization in connection with the residual stress and interfacial reliability. The thermal stress induced crack formation and propagation could be investigated by performing simulation using more powerful numerical model in the follow-up studies.

\section{REFERENCES}

[1] P. Swaminathan, M. D. Grapes, K. Woll, S. C. Barron, D. A. LaVan, T. P. Weihs, "Studying exothermic reactions in the Ni-Al system at rapid heating rates using a nanocalorimeter," J. Appl. Phys., vol. 113, no. 14, p 143509, Apr. 2013.

[2] K. Wang, K. Ruan, W. Hu, S. Wu, H. Wang, "Room temperature bonding of $\mathrm{GaN}$ on diamond wafers by using $\mathrm{Mo} / \mathrm{Au}$ nano-layer for high-power semiconductor devices," Scr. Mater., vol. 174, pp. 87-90, Jan. 2020.

[3] Y. C. Liu, S. K. Lin, H. Zhang, S. Nagao, C. Chen, K. Suganuma, "Reactive wafer bonding with nanoscale $\mathrm{Ag} / \mathrm{Cu}$ multilayers," Scr. Mater., vol. 184, pp. 1-5, Jul. 2020.

[4] W. Zhu, X. Wang, C. Liu, Z. Zhou, F. Wu, "Formation and homogenisation of $\mathrm{Sn} \mathrm{Cu}$ interconnects by self-propagated exothermic reactive bonding," Mater. Des., vol. 174, p. 107781, Jul. 2019.

[5] X. Wang, M. Li, W. Zhu, "Formation and homogenization of $\mathrm{Si}$ interconnects by non-equilibrium self-propagating exothermic reaction," J. Alloys Compd., vol. 817, p. 153210, Mar. 2020.

[6] S. Kanetsuki, S. Miyake, T. Namazu, "Effect of free-standing Al/Ni exothermic film on thermal resistance of reactively bonded solder joint," Sens. Mater., vol. 31, no. 3, pp. 729-741, Mar. 2019.

[7] J. Wang, E. Besnoin, A. Duckham, S. J. Spey, M. E. Reiss, O. M. Knio, T. P. Weihs, "Joining of stainless-steel specimens with nanostructured Al/Ni foils," J. Appl. Phys., vol. 95, pp. 248-256, Jan. 2004.

[8] I. E. Gunduz, K. Fadenberger, M. Kokonou, C. Rebholz, C. C. Doumanidis, "Investigations on the self-propagating reactions of nickel and aluminum multilayered foils," Appl. Phys. Lett., vol. 93, no. 13, pp. 134101, Sep. 2008.

[9] O. Mokhtari, "A review: Formation of voids in solder joint during the transient liquid phase bonding process-Causes and solutions," Microelectron. Reliab., vol. 98, pp. 95-105, Jul. 2019.

[10] S. Kanetsuki, S. Miyake, T. Namazu, "Effect of free-standing Al/Ni exothermic film on thermal resistance of reactively bonded solder joint," Sensors and Materials, vol. 31, no. 3, pp. 729-741, Mar. 2019.

[11] S. Liang, Y. Zhong, S. Robertson, A. Liu, Z. Zhou, C. Liu, "Investigation of Thermo-mechanical and Phase-change Behavior in the $\mathrm{Sn} / \mathrm{Cu}$ Interconnects during Self-Propagating Exothermic Reaction Bonding," in Proc. IEEE 70th Electron. Compon. Technol. Conf., May 2020, pp. 269-275.

[12] T. Fiedler, I. V. Belova, S. Broxtermann, G. E. Murch, "A thermal analysis on self-propagating high temperature synthesis in joining technology," Comput. Mater. Sci., vol. 53, no. 1, pp. 251-257, Feb. 2012.

[13] C. D. Zou, Y. L. Gao, B. Yang, X. Z. Xia, Q. J. Zhai, C. Andersson, J. Liu, "Nanoparticles of the Lead-free Solder Alloy Sn-3.0Ag- $0.5 \mathrm{Cu}$ with Large Melting Temperature Depression," J. Electron. Mater., vol. 38, no. 2, pp. 351-355, Oct. 2008.

[14] W. Sanhye, C. Dubois, I. Laroche, P. Pelletier, "Numerical modeling of the cooling cycle and associated thermal stresses in a melt explosive charge," AICHE J., vol. 62, no. 10, pp. 3797-3811, May 2016.

[15] B. Hu et al., "Failure and Reliability Analysis of a SiC Power Module Based on Stress Comparison to a Si Device," IEEE Trans. Device Mater. Reliab., vol. 17, no. 4, pp. 727-737, Dec. 2017.

[16] J. R. Rice, "A Path Independent Integral and the Approximate Analysis of Strain Concentration by Notches and Cracks," J. Appl. Mech., vol. 35, no. 2, pp. 379-386, Jun. 1968.

[17] R. J. Bruls, H. T. Hintzen, G. de With, R. Metselaar, "The temperature dependence of the Young's modulus of $\mathrm{MgSiN}_{2}, \mathrm{AlN}$ and $\mathrm{Si}_{3} \mathrm{~N}_{4}$," J. Eur. Ceram. Soc., vol. 21, no. 3, pp. 263-268, Mar. 2001.

[18] A. M. Hodge, D. C. Dunand, "Measurement and modeling of creep in open-cell NiAl foams," Metall. Mater. Trans. A, vol. 34, no. 10, pp. 2353-2363, Oct. 2003.

[19] J. Wang, E. Besnoin, O. M. Knio, T. P. Weihs, "Effects of physical properties of components on reactive nanolayer joining," J. Appl. Phys., vol. 97, no. 11, p. 114307, Jun. 2005.

[20] H. Kröncke, S. Figge, D. Hommel, B. M. Epelbaum, "Determination of the Temperature Dependent Thermal Expansion Coefficients of Bulk 
AIN by HRXRD,” Acta Phys. Pol., vol. 114, no. 5, pp. 1193-1200, Nov. 2008.

[21] C. H. Cho, "Characterization of Young's modulus of silicon versus temperature using a 'beam deflection' method with a four-point bending fixture," Curr. Appl. Phys., vol. 9, no. 2, pp. 538-545, Mar. 2009.

[22] A. Yakymovych, H. Weber, I. Kaban, H. Ipser, "Dynamic viscosity of a liquid Sn-3.0Ag-0.5Cu alloy with Ni nanoparticles," J. Mol. Liq., vol. 268, pp. 176-180, Oct. 2018.

[23] C. S. Lau, M. Z. Abdullah, F. C. Ani, "Effect of Solder Joint Arrangements on BGA Lead-Free Reliability During Cooling Stage of Reflow Soldering Process," IEEE Trans. Electron. Packag. Manuf., vol. 2, no. 12, pp. 2098-2107, Dec. 2012s.

[24] J. Fan, T. Shi, Z. Tang, B. Gong, J. Li, J. Huang, T. Li, "LowTemperature $\mathrm{Cu}-\mathrm{Cu}$ Bonding Process Based on the $\mathrm{Sn}-\mathrm{Cu}$ Multilayer and Self-Propagating Reaction Joining," J. Electron. Mater., vol. 48, no. 2, pp. 1310-1317, Dec. 2018.

[25] T. Mukherjee, W. Zhang, T. DebRoy, "An improved prediction of residual stresses and distortion in additive manufacturing," Comput. Mater. Sci., vol. 126, pp. 360-372, Jan. 2017.

[26] Y. Liu, Thermal Stress Migration and Its Role in Electromigration of Microelectronics. In: Hetnarski R.B. (eds) Encyclopedia of Thermal Stresses, Springer, Dordrecht, 2014.

[27] S. H. Rhee, Y. Du, P. S. Ho, "Thermal stress characteristics of Cu/oxide and Cu/low-k submicron interconnect structures," J. Appl. Phys., vol. 93 no. 7, pp. 3926-3933, Apr. 2003.

[28] J. Fan, T. Shi, X. Tao, T. Zhou, J. Li, Z. Tang, G. Liao, X. Yu, "The Cu -Cu self-propagating reaction joining with different thickness of tin," J. Alloys Compd., vol. 735, pp. 1189-1194, Feb. 2018.

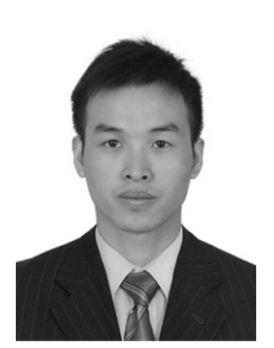

Shuibao Liang received the B.E. degree from Wuhan University of Science and Technology, Wuhan, China, in 2012, and the Ph.D. degree from South China University of Technology, Guangzhou, China, in 2019.

$\mathrm{He}$ is currently a Research Associate with the Wolfson School of Mechanical, Electrical and Manufacturing Engineering, Loughborough University, Loughborough, U.K.

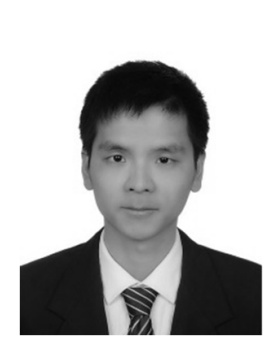

Yi Zhong received the B.E. degree from Nanchang Hangkong University, Nanchang, China, in 2013, and the Ph.D. degree from Dalian University of Technology, Dalian, China, in 2018.

From 2018 to 2020, he was a Research Associate with the Wolfson School of Mechanical, Electrical and Manufacturing Engineering, Loughborough University, Loughborough, U.K. In 2020, He joined the Xiamen university, as an Assistant Professor.

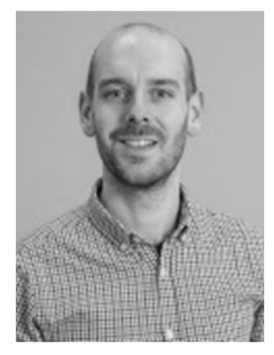

Stuart Robertson received a M.Eng. and Ph.D. degrees from Loughborough University, Loughborough, U.K., in 2014 and 2018, respectively.

From 2018 to 2020, he was a Research Associate with in the Wolfson School of Mechanical, Electrical and Manufacturing Engineering, Loughborough University, Loughborough, U.K. He is currently a technical specialist in ion and electron microscopy at the Loughborough materials characterization center (LMCC).

Allan Liu received his B.E. degree from Coventry University, Coventry, U.K., in 2019. He is currently pursuing a Ph.D. degree with the Department of Mechanical Engineering, The University of Sheffield, Sheffield, U.K.

In 2018, and from 2019 to 2020, he was a Research Assistant with the Wolfson School of Mechanical, Electrical and Manufacturing Engineering, Loughborough University, Loughborough, U.K.

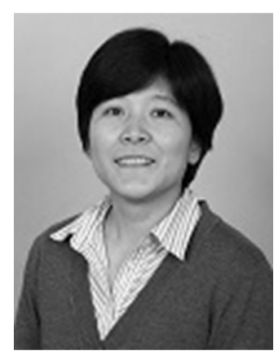

Zhaoxia Zhou received the B.Eng. and M.Eng. degrees from Harbin Institute of Technology, Harbin, China, in 1997, and Ph.D. degrees from Institute of Metal Research, Chinese Academy of Sciences and The University of Sheffield in 2010.

She is a Research Fellow in materials characterization at Loughborough Materials Characterization Centre, Department of Materials, Loughborough University. One of her research areas is applying electron microscopy and X-ray related techniques to understand interfaces at heterogeneously integrated materials in electronics for optimized thermal, electrical and mechanical performance.

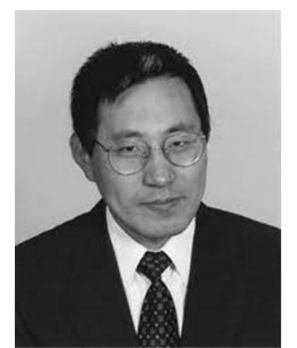

Changqing Liu received his B.Eng. degree in 1985 from the Nanjing University of Science and Technology, Nanjing, China, M.Sc. degree in 1988 from the Chinese Academy of Science, Beijing, China, and his Ph.D. degree in 1998 from Hull University, Hull, U.K.

He was an Assistant Professor with the Institute of Metals Research, Chinese Academy of Science. From 1993, he secured an Overseas Research Scholarship and moved to the U.K. for his PhD study. In 1997, he joined Birmingham University, U.K., as a Post-Doctoral Research Fellow for 3 years. In 2000, he joined the Wolfson School of Mechanical, Electrical and Manufacturing Engineering, Loughborough University, U.K., where he has been a Professor of electronics manufacture since 2011, after his appointments as a Lecturer in 2005, and a Senior Lecturer in 2007. He has authored over 242 academic papers. His current research interests include advanced materials and innovative manufacturing to enable 3-D multimaterial heterogeneous embodiment, integration, and miniaturization of future generation multifunctional devices.

Dr. Liu is currently a Fellow of the Higher Education Academy, U.K., an IEEE Senior Member, and previously served as the Chair of the Interconnections Committee of ECTC (USA) and the Chair of Packaging Materials and Processes Committee of ICEPT (China). 